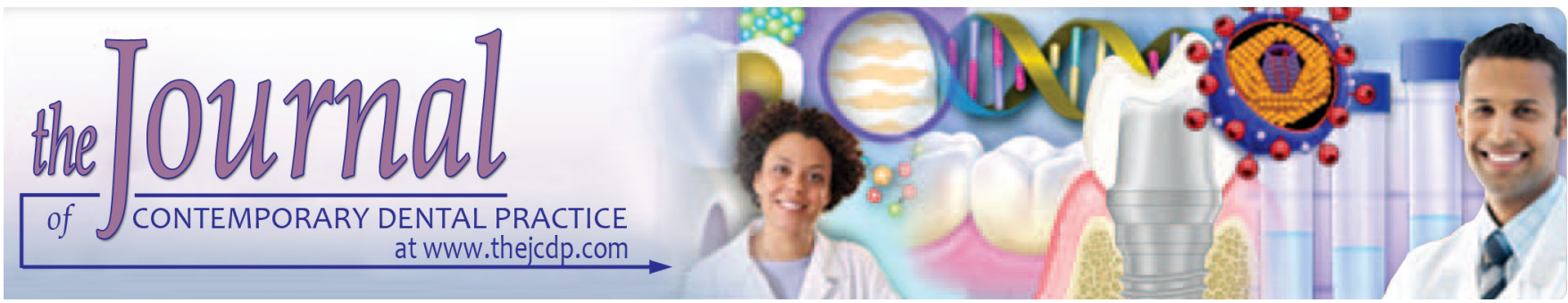

\title{
Skeletal Age-related Changes of Midpalatal Suture Densities in Skeletal Maxillary Constriction Patients: CBCT Study
}

\author{
${ }^{1}$ Dani A Samra, ${ }^{2}$ Rania Hadad
}

\begin{abstract}
Aim: To determine if density measurements of the midpalatal suture and cervical vertebral maturation index (CVMI) are related, and to investigate if CVMI could help in predicting of the developmental status of the midpalatal suture.
\end{abstract}

Materials and methods: Cone-beam computed tomography (CBCT) images of 95 skeletal maxillary constriction patients (aged 8 to 18 years) were examined. The maturational stages of the cervical vertebrae were visually defined, and midpalatal suture density in the anterior region, the middle region, and the posterior region were measured. One-way ANOVA and Fisher's least significant difference (LSD) post-hoc test were used for statistical assessment.

Results: Significant differences were found in MPDS: in anterior region between $(\mathrm{c} 1, \mathrm{c} 2, \mathrm{c} 3, \mathrm{c} 4)$ and $(\mathrm{c} 5, \mathrm{c} 6)$ stages, in middle region between $(\mathrm{c} 1, \mathrm{c} 2, \mathrm{c} 3)$ and $(\mathrm{c} 5, \mathrm{c} 6)$ stages, and in posterior region between $(\mathrm{c} 1, \mathrm{c} 2, \mathrm{c} 3)$ and $(\mathrm{c} 4, \mathrm{c} 5, \mathrm{c} 6)$ stages.

Conclusion: Midpalatal suture densities in all regions increase with skeletal maturation advancement.The significant increase after puberty may have the key role in decreasing the skeletal effects of RME after that age.

Clinical significances: It is important to assess the midpalatal suture density to choose between rapid maxillary expansion (RME) and surgically assisted rapid maxillary expansion (SARME). This study revealed a significant increase in the midpalatal suture density after puberty. Thus, it may better to perform RME before puberty.

Keywords: Cervical vertebral maturation index, Cone-beam computed tomography, Midpalatal suture, Rapid maxillary expansion, Surgically assisted rapid maxillary expansion.

\footnotetext{
1,2Department of Orthodontics and Dentofacial Orthopaedics, Faculty of Dental Medicine, Damascus University, Damascus, Syria.
}

Corresponding Author: Dani A Samra, Department of Orthodontics and Dentofacial Orthopaedics, Faculty of Dental Medicine, Damascus University, Damascus, Syria, Mobile: 00963988297169, e-mail: daniabosamra89@gmail.com)
How to cite this article: Samra DA, Hadad R. Skeletal Agerelated Changes of Midpalatal Suture Densities in Skeletal Maxillary Constriction Patients: CBCT Study. The Journal of Contemporary Dental Practice, October 2018;19(10):1260-1266.

Source of support: Nil

Conflict of interest: None

\section{INTRODUCTION}

Transverse maxillary deficiency (TMD) is a frequent component of malocclusions. ${ }^{1-3}$ Rapid maxillary expansion (RME) was first documented in 1860 by Angell $^{4}$ and reintroduced in 1961 by Hass as a common procedure to treat TMD during the growth spurt. ${ }^{5,6}$

Opening the midpalatal suture (MPS) could be easily achieved using an expansion device in a young child, but it needs a relatively heavy force generated by a rigid jackscrew device to accomplish RME inadolescence. ${ }^{2}$ After adolescence, it is usually necessary to perform surgically assisted RME (SARME) to reduce the resistance of suture to expansion. ${ }^{2,3}$ However, the time point to shift from RME to SARME is not clear enough especially in young adults. ${ }^{7-9}$ Since chronological age seems to be unreliable, ${ }^{8-10}$ some studies suggested using the hand wrist radiographic ${ }^{11}$ or cervical vertebrae maturation index $(\mathrm{CVMI})^{12,13}$ to make such a decision. Whereas, other studies assumed that skeletal age should not be depended on. 8,14

Although midpalatal suture is suggested to be the region of the greatest resistance to maxillary expansion, ${ }^{15}$ Knaup et al. ${ }^{9}$ found that the obliteration index (OI) of MPS may not be a valid reason for increasing that resistance with advancing age because it remains low even in patients aged ( $>26$ years). On the contrary, the density of the midpalatal suture (MPSD) is likelyto be the most important factor determining the necessity for surgical weakening rather than OI.,16 Similarly Grünheid et al. ${ }^{14}$ 
assured that MPSD ratio has the potential to become a useful clinical predictor of skeletal response to RME.

On the other hand, a recent cone beam computed tomography (CBCT) studyrevealed a new five-stage classification according to the morphology of MPS that could be relied onto choose between RME and SARME in late adolescents and young adults. ${ }^{17}$ The stages of this classification are related to cervical vertebrae maturational stages (CVMs). ${ }^{12}$ Moreover, the latest studies in the discipline concluded that individual evaluation of MPS maturation on CBCT images in adults may provide reliable parameters for the clinical decision between RME and SARME. ${ }^{18}$ For instance, when assessment of the sutural status indicates stage $C$, conventional RME treatment is justified and would have a satisfactory prognosis in patients over 15 years. ${ }^{19}$

None of the studies in the literature explored the MPSD in relation to skeletal maturation. Thus, this study aimed at determining the changes of MPSDs according to CVMI.

\section{MATERIALS AND METHODS}

This study was a retrospective study for analytical purpose. It was done in the Department of Orthodontics at the University of Damascus Dental School, Damascus, Syria. The archived CBCT scans of 95 patients (mean age $12.69 \pm 2.87$ years; range 8.1 to 17.8 years; 48 females and 47 males), were evaluated retrospectively from August 2015 to February 2017, with the following inclusion criteria: patients must be aged 8 to 18 years and have a skeletal maxillary constriction. Patients with congenital disorders, systemic diseases, maxillofacial deformities or previous orthodontic treatment were excluded. Those images had been required for diagnosis and treatment planning by the orthodontists where the study took place. Ethical approval was obtained from the Ethics Committee at the Ministry of Higher Education in Syria (1749/SM).

All CBCT scans were performed in the same radiographic clinic using the Scanora $3 \mathrm{D}$ device with 85 $\mathrm{kV}, 15 \mathrm{~mA}$, and 2.25 seconds exposure time. The field of view was $14 \times 7 \mathrm{~cm}$. The scan data were reconstructed with a voxel size of $0.3 \mathrm{~mm}^{3}$. Dicoms data were processed with OnDemand $\AA$ 3D software viewer v1.0 (CyberMed, Finland).

Measurements were performed after standardizing the CBCT radiograph (Fig. 1) at both the midsagittal slice (the horizontal axis passed through anterior and posterior nasal spine) and the axial slice (the vertical axis passed through anterior and posterior nasal spine).

Lateral cephalograms were derived from CBCT images. Images of the cervical vertebrae were cropped, and the images of the dentition or skeletal structures were removed. The cropped images were arranged in a Power Point presentation with a black background and identification codes. The vertebral images were classified by the same examiner according to Baccetti et al. ${ }^{20}$ classification of CVMs to six stages from $\mathrm{c} 1$ to $\mathrm{c} 6$ (Fig. 2 and Table 1).

\section{Midpalatal Suture Density Measurements}

On sagittal slice passing through the anterior and posterior nasal spine, four points were determined as follows: (Fig. 3 )

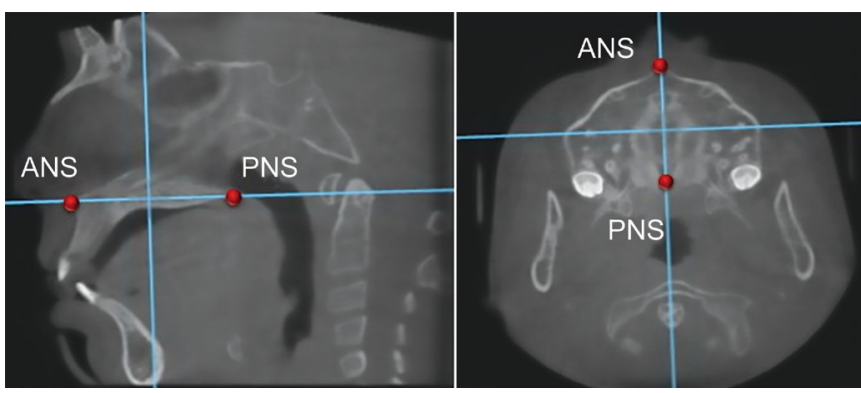

Fig. 1: Standardization of $C B C T$ radiograph in axial and sagittal planes

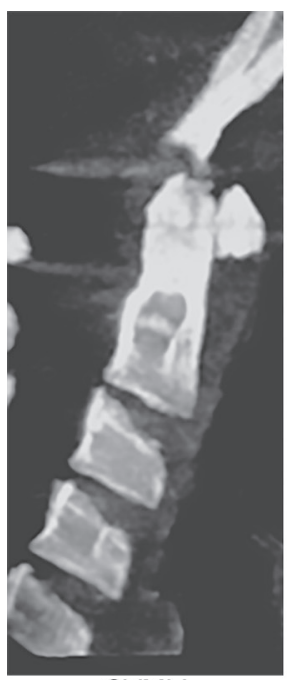

CVMI I

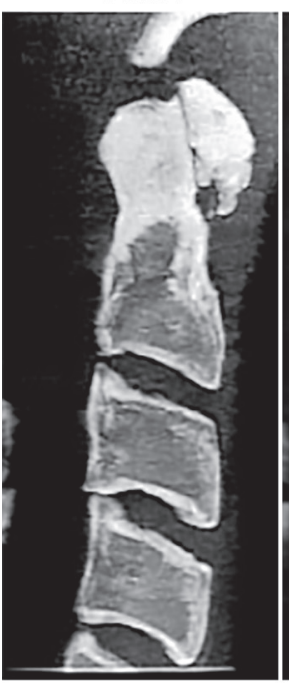

CVMI IV

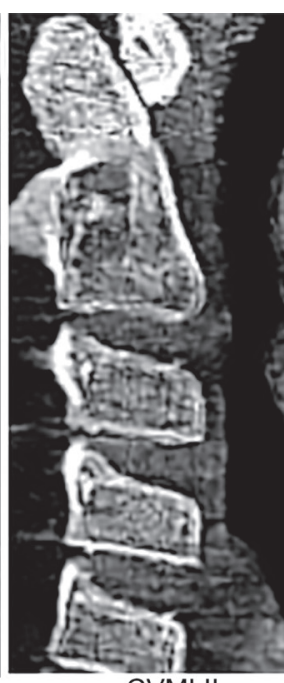

CVMI II

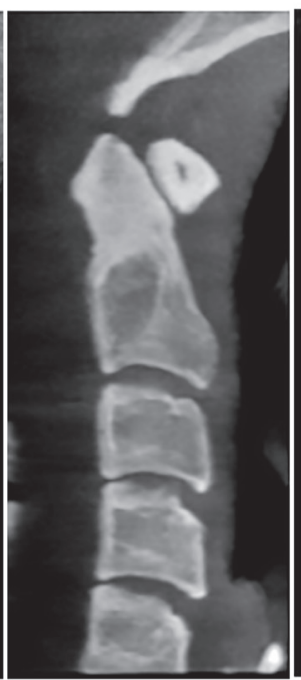

CVMI V

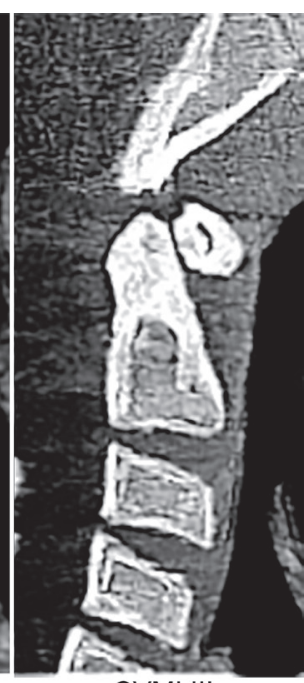

CVMI III

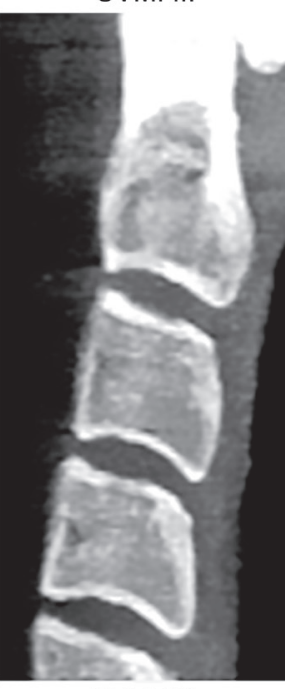

CVMI VI
Fig. 2: Six stages of cervical vertebral maturation. 
Table 1: Sample distribution according to skeletal maturation stage

\begin{tabular}{lll}
\hline Skeletal maturation stage & Subjects no & Percent \\
\hline C1 & 15 & 15.8 \\
C2 & 15 & 15.8 \\
C3 & 17 & 17.9 \\
C4 & 13 & 13.7 \\
C5 & 17 & 17.9 \\
C6 & 18 & 18.9 \\
Total & 95 & 100 \\
\hline
\end{tabular}

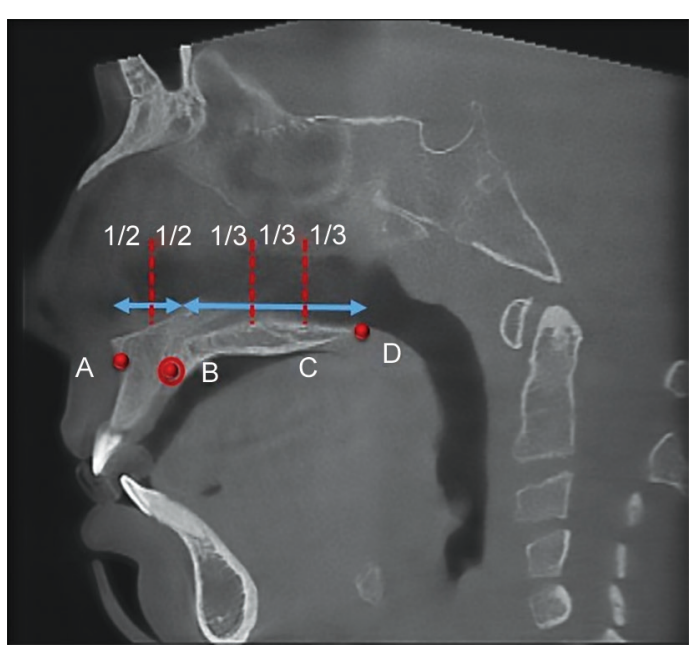

Fig. 3: Four points determined on the sagittal slice.

A point: the most posterior point at the anterior edge of the maxilla alveolar process.

$B$ point: center of the incisive foramen.

$D$ point: the most posterior point at the posterior edge of the hard palate.

$C$ point: the distance between $\mathrm{B}$ and $\mathrm{D}$ was divided into three thirds and the point $C$ was at the junction between the anterior two third and the posterior third.

Then on the coronal slice, using On Demand 3D App, the mean MPSD value was determined using a rectangle region of interest (ROI) at $5 \mathrm{~mm}$ in width and along the full height of MPS.

Three rectangles were drawn at three positions: the mid-distance between A-Bto measure anterior MPS

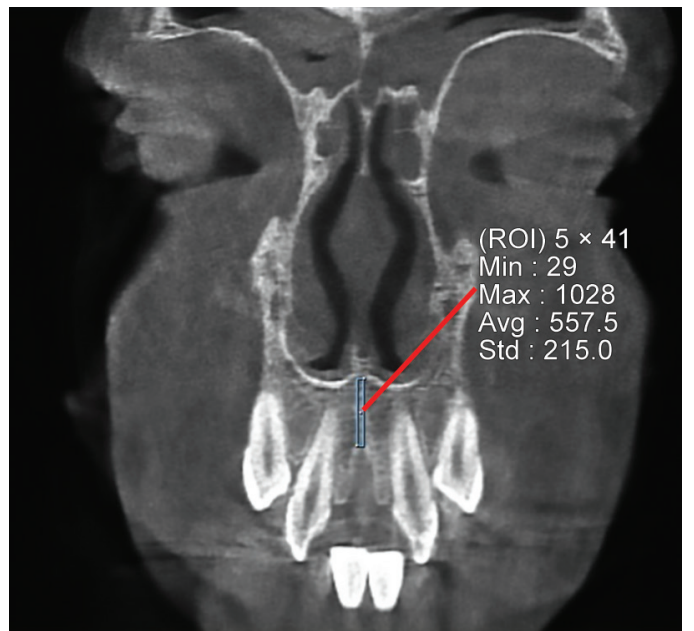

Fig. 4: Measurement of MPSD in the anterior region. density (MPSDa) (Fig. 4 ), the mid-distance between B-C to measure middle MPS density (MPSDm) (Fig. 5 ), and the mid-distance between C-D to measure posterior MPS density (MPSDp) (Fig. 6 ).

\section{Method Error}

Thirty CBCT scans of thetotal sample were selected randomly, Cervical vertebrae were reclassified and MPSD measurements in all regions of MPS were repeated by the same examiner a month later.

\section{Statistical Analysis}

A weighted kappa coefficient was calculated to evaluate the intra-examiner agreement for the CVM method.

The intraclass correlation coefficient (ICC) was used to assess intra-examiner reliability for MPDS measurements.

Data were analyzed using SPSS13.0 edition. One-way ANOVA, Fisher's least significant difference LSD post-hoc tests were used for pairwise significant difference in bone density values. Statistical significance was determined at $\mathrm{p}<0.05$.

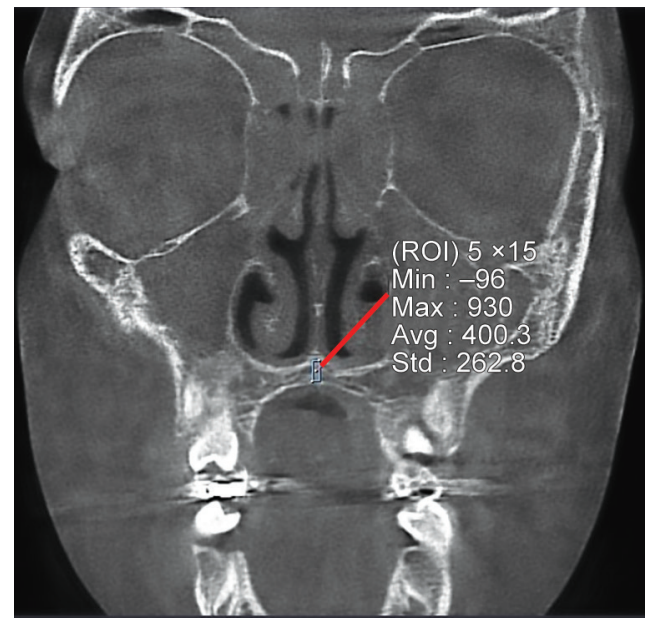

Fig. 5: Measurement of MPSD in the middle region.

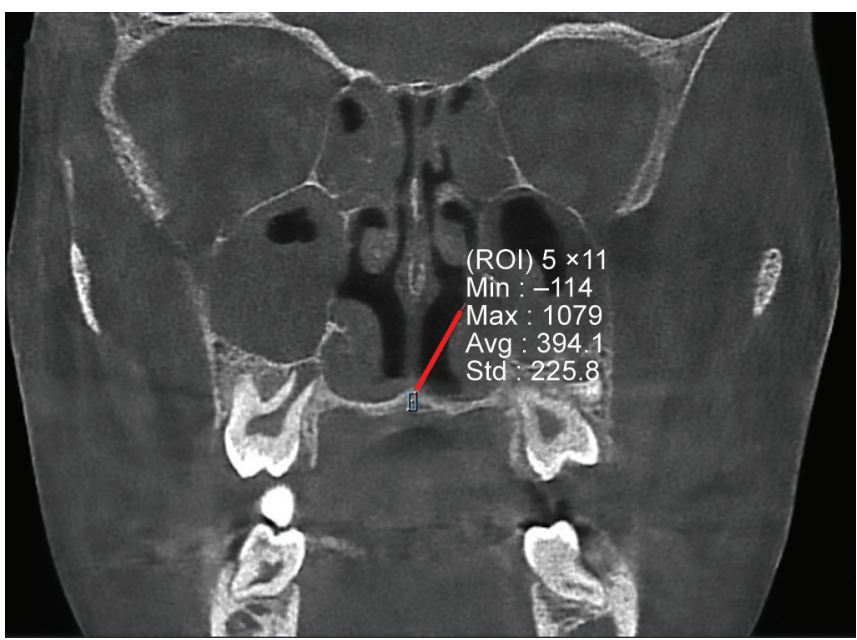

Fig. 6: Measurement of MPSD in the posterior region. 


\section{RESULTS}

The weighted kappa coefficients for the evaluation of the intraexaminer agreement for the CVM method was 0.98. This result reveals almost perfect intra examiner reproducibility according to the scale of Landis and Koch. ${ }^{21}$

The results of the intraclass correlation coefficient (ICC) test revealed high reliability between the two assessments for density measurements in all regions $(\mathrm{ICC}>0.8)$.

The bone density minimum, maximum, mean and standard deviation values are summarized in (Table 2).

Table 2: Minimum, maximum, mean, and standard deviations values for the midpalatal suture density measurements in the six skeletal maturation stages

\begin{tabular}{|c|c|c|c|c|c|c|}
\hline $\begin{array}{l}\text { Studied } \\
\text { location }\end{array}$ & $\begin{array}{l}\text { Skele- } \\
\text { tal } \\
\text { matur- } \\
\text { ation } \\
\text { stage }\end{array}$ & Mean & $\begin{array}{l}\text { Std. } \\
\text { devia- } \\
\text { tion }\end{array}$ & $\begin{array}{l}\text { Mini- } \\
\text { mum }\end{array}$ & $\begin{array}{l}\text { Maxi- } \\
\text { mum }\end{array}$ & $p$-value \\
\hline \multirow{6}{*}{ Anterior } & C1 & 317.47 & 209.58 & 13 & 786 & \multirow{6}{*}{$<0.001^{* * *}$} \\
\hline & $\mathrm{C} 2$ & 353.47 & 149.96 & 71 & 597 & \\
\hline & C3 & 418.41 & 220.47 & 196 & 978 & \\
\hline & $\mathrm{C} 4$ & 421.08 & 111.29 & 232 & 678 & \\
\hline & C5 & 567.88 & 197.40 & 142 & 919 & \\
\hline & $\mathrm{C} 6$ & 619.06 & 201.52 & 290 & 1114 & \\
\hline \multirow{6}{*}{ Middle } & $\mathrm{C} 1$ & 284.47 & 246.68 & -162 & 633 & \multirow{6}{*}{$0.009^{* *}$} \\
\hline & $\mathrm{C} 2$ & 348.53 & 178.22 & 86 & 688 & \\
\hline & $\mathrm{C} 3$ & 373.86 & 322.21 & 44 & 1165 & \\
\hline & C4 & 384.38 & 268.65 & -68 & 865 & \\
\hline & C5 & 547.18 & 230.28 & 9 & 918 & \\
\hline & C6 & 549.39 & 188.04 & 345 & 1067 & \\
\hline \multirow{6}{*}{ Posterior } & $\mathrm{C} 1$ & 370.80 & 253.25 & -77 & 685 & \multirow{6}{*}{$<0.001^{* * *}$} \\
\hline & $\mathrm{C} 2$ & 424.60 & 222.76 & 68 & 866 & \\
\hline & C3 & 456.46 & 251.97 & 93 & 792 & \\
\hline & $\mathrm{C} 4$ & 677.77 & 252.82 & 268 & 1236 & \\
\hline & C5 & 695.41 & 255.10 & 281 & 1257 & \\
\hline & C6 & 760.33 & 283.11 & 224 & 1287 & \\
\hline
\end{tabular}

${ }^{*} \mathrm{p}<0.05,{ }^{* *} \mathrm{p}<0.01,{ }^{* * *} \mathrm{p}<0.001$

Density measurements were evaluated according to skeletal age. The MPSD increased in all regions with the advancement of skeletal maturation.

Significant differences were found in MPSD as follows: Between $(\mathrm{c} 1, \mathrm{c} 2, \mathrm{c} 3, \mathrm{c} 4)$ and $(\mathrm{c} 5, \mathrm{c} 6)$ stages in MPSDa (Table 3), between (c1,c2,c3) and (c5,c6) stages in MPSDm (Table 4), and between $(\mathrm{c} 1, \mathrm{c} 2, \mathrm{c} 3)$ and $(\mathrm{c} 4, \mathrm{c} 5, \mathrm{c} 6)$ stages in MPSDp (Table 5).

\section{DISCUSSION}

Several studies have proposed various methods for assessing bone density. More recently, CBCT has been widely employed in oral and maxillofacial imaging as well as in the measurement of bone density. ${ }^{22-27}$ Although
Table 3: Differences of midpalatal suture density measurements in the anterior region among skeletal maturation stages (LSD posthoc test)

\begin{tabular}{|c|c|c|c|c|c|}
\hline $\begin{array}{l}\text { Studied } \\
\text { location }\end{array}$ & $\begin{array}{l}\text { Skeletal } \\
\text { maturation } \\
\text { stage (I) }\end{array}$ & $\begin{array}{l}\text { Skeletal } \\
\text { matu- } \\
\text { ration } \\
\text { stage }(\mathrm{J})\end{array}$ & $\begin{array}{l}\text { Mean } \\
\text { difference } \\
(I-J)\end{array}$ & $\begin{array}{l}\text { Std. } \\
\text { error }\end{array}$ & $p$-value \\
\hline \multirow{15}{*}{ Anterior } & \multirow{5}{*}{$\mathrm{C} 1$} & $\mathrm{C} 2$ & -36.00 & 68.91 & 0.603 \\
\hline & & C3 & -100.95 & 66.86 & 0.135 \\
\hline & & $\mathrm{C} 4$ & -103.61 & 71.51 & 0.151 \\
\hline & & C5 & -250.42 & 66.86 & $<0.001^{\star * *}$ \\
\hline & & C6 & -301.59 & 65.98 & $<0.001^{* * *}$ \\
\hline & \multirow{4}{*}{$\mathrm{C} 2$} & C3 & -64.95 & 66.86 & 0.334 \\
\hline & & $\mathrm{C} 4$ & -67.61 & 71.51 & 0.347 \\
\hline & & C5 & -214.42 & 66.86 & $0.002^{* *}$ \\
\hline & & C6 & -265.59 & 65.98 & $<0.001^{* * *}$ \\
\hline & \multirow{3}{*}{ C3 } & $\mathrm{C} 4$ & -2.67 & 69.53 & 0.970 \\
\hline & & C5 & -149.47 & 64.73 & $0.023^{*}$ \\
\hline & & C6 & -200.64 & 63.83 & $0.002^{* *}$ \\
\hline & \multirow{2}{*}{$\mathrm{C} 4$} & C5 & -146.81 & 69.53 & $0.038^{*}$ \\
\hline & & $\mathrm{C} 6$ & -197.98 & 68.69 & $0.005^{* *}$ \\
\hline & C5 & C6 & -51.17 & 63.83 & 0.425 \\
\hline
\end{tabular}

Table 4: Differences of midpalatal suture density measurements in the middle region among skeletal maturation stages (LSD posthoc Test)

\begin{tabular}{|c|c|c|c|c|c|}
\hline $\begin{array}{l}\text { Studied } \\
\text { Iocation }\end{array}$ & $\begin{array}{l}\text { Skeletal } \\
\text { maturation } \\
\text { stage (I) }\end{array}$ & $\begin{array}{l}\text { Skeletal } \\
\text { maturation } \\
\text { stage }(\mathrm{J})\end{array}$ & $\begin{array}{l}\text { Mean differ- } \\
\text { ence (I-J) }\end{array}$ & $\begin{array}{l}\text { Std. } \\
\text { error }\end{array}$ & $p$-value \\
\hline \multirow{15}{*}{ Middle } & \multirow{5}{*}{ C1 } & $\mathrm{C} 2$ & -64.07 & 88.88 & 0.473 \\
\hline & & C3 & -89.40 & 86.23 & 0.303 \\
\hline & & $\mathrm{C} 4$ & -99.92 & 92.24 & 0.282 \\
\hline & & C5 & -262.71 & 86.23 & $0.003^{* *}$ \\
\hline & & C6 & -264.92 & 85.10 & $0.002^{* *}$ \\
\hline & \multirow{4}{*}{$\mathrm{C} 2$} & C3 & -25.33 & 86.23 & 0.770 \\
\hline & & C4 & -35.85 & 92.24 & 0.698 \\
\hline & & C5 & -198.64 & 86.23 & $0.024^{*}$ \\
\hline & & C6 & -200.86 & 85.10 & $0.020^{*}$ \\
\hline & \multirow{3}{*}{ C3 } & $\mathrm{C} 4$ & -10.52 & 89.68 & 0.907 \\
\hline & & C5 & -173.31 & 83.49 & $0.041^{*}$ \\
\hline & & C6 & -175.52 & 82.32 & $0.036^{*}$ \\
\hline & \multirow{2}{*}{$\mathrm{C} 4$} & C5 & -162.79 & 89.68 & 0.073 \\
\hline & & C6 & -165.00 & 88.60 & 0.066 \\
\hline & C5 & C6 & -2.21 & 82.32 & 0.979 \\
\hline
\end{tabular}

${ }^{*} \mathrm{p}<0.05,{ }^{* *} \mathrm{p}<0.01,{ }^{* * *} \mathrm{p}<0.001$

low standardization between CBCT machines exists, and the Hounsfield scale may vary among studies, ${ }^{28}$ a recent study stated that "exposure protocols from certain devices show stable grey values that could be related to HU and density." 29 Therefore, the current study aimed at comparing the bone density measurements of $\mathrm{CBCT}$ images taken by one device (Scanora 3D) rather than revealing the exact values of MPSD. Moreover, a strong linear correlation between the voxel grey values from Scanora 3D device and actual Hounsfield units derived from (HU) multislice CT was determined. ${ }^{29}$ Similarly, 
Table 5: Differences of midpalatal suture density measurements in the posterior region among skeletal maturation stages (LSD post-hoc test)

\begin{tabular}{|c|c|c|c|c|c|}
\hline $\begin{array}{l}\text { Studied } \\
\text { location }\end{array}$ & $\begin{array}{l}\text { Skeletal } \\
\text { maturation } \\
\text { stage (I) }\end{array}$ & $\begin{array}{l}\text { Skeletal } \\
\text { maturation } \\
\text { stage }(\mathrm{J})\end{array}$ & $\begin{array}{l}\text { Mean } \\
\text { ddiffer- } \\
\text { ence } \\
(I-J) \\
\end{array}$ & $\begin{array}{l}\text { Std. } \\
\text { error }\end{array}$ & $p$-value \\
\hline \multirow{15}{*}{ Posterior } & \multirow{5}{*}{ C1 } & $\mathrm{C} 2$ & -53.80 & 93.05 & 0.565 \\
\hline & & $\mathrm{C} 3$ & -85.66 & 90.27 & 0.345 \\
\hline & & $\mathrm{C} 4$ & -306.97 & 96.56 & $0.002^{* *}$ \\
\hline & & C5 & -324.61 & 90.27 & $0.001^{* *}$ \\
\hline & & $\mathrm{C} 6$ & -389.53 & 89.09 & $<0.001^{* * *}$ \\
\hline & \multirow{4}{*}{$\mathrm{C} 2$} & C3 & -31.86 & 90.27 & 0.725 \\
\hline & & $\mathrm{C} 4$ & -253.17 & 96.56 & $0.0103^{*}$ \\
\hline & & C5 & -270.81 & 90.27 & $0.004^{* *}$ \\
\hline & & C6 & -335.73 & 89.09 & $<0.001^{* * *}$ \\
\hline & \multirow{3}{*}{ C3 } & $\mathrm{C} 4$ & -221.31 & 93.89 & $0.021^{*}$ \\
\hline & & C5 & -238.95 & 87.40 & $0.008^{* *}$ \\
\hline & & C6 & -303.87 & 86.18 & $0.001^{* *}$ \\
\hline & \multirow{2}{*}{$\mathrm{C} 4$} & C5 & -17.64 & 93.89 & 0.851 \\
\hline & & $\mathrm{C} 6$ & -82.56 & 92.75 & 0.376 \\
\hline & C5 & $\mathrm{C} 6$ & -64.92 & 86.18 & 0.453 \\
\hline
\end{tabular}

${ }^{*} p<0.05,{ }^{* *} p<0.01,{ }^{* * *} p<0.001$

many studies reported the existence of strong linear correlations of the voxel gray values of $\mathrm{CBCT}$ image with $\mathrm{HU}$ of multislice $\mathrm{CT}$ as a clinical reference. . $2,30-33^{-}$

RME is widely used to treat TMD in children and young patients ${ }^{7}$ while SARME is recommended in skeletally mature patients. ${ }^{3}$ However, there is a lack of definitive guidelines to choose between RME and SARME in young adults. ${ }^{3}$

Although initial studies of MPS considered the OI as the limiting factor to determine the treatment choice, most of these studies failed to find a direct relationship between OI and chronological or skeletal age. ${ }^{8,9,11}$ Recent studies suggested that morphological stages of the MPS and their relationship to CVMI could be a reliable parameter ${ }^{12,17}$ but no clinical studies confirmed that yet. ${ }^{14}$

On the other hand, because of the proportional relationship between bone density and its resistance to fractures, and the increase of MPSD values with age, it has been suggested that MPSD is the most reliable reason to explain the increase -with age- maxillary resistance to expansion. ${ }^{8}$ Moreover a recent clinical study by Grünheid et al. ${ }^{14}$ found a statistically significant negative correlation between the MPSD and the skeletal effects of RME, and concluded that MPSD has the potential to be a useful clinical predictor of skeletal response to RME. In accordance with this, the findings of the current study showed a positive relationship between MPDS and CVMI in all MPS regions. This may explain the difficulty to gain skeletal effects of RME in most mature patients. Korbmacher et al. ${ }^{8}$ also explained that the necessity for surgical weakening can neither be explained by sutural interdigitation increasing with age nor by a higher obliteration index. They concluded that the MPSD, which is the only age-related dependent parameter, seems to be the most important limiting factor for the treatment choice.

The results of this study showed that there were significant differencesin MPSDa after (c4) stage,in MPSDm between (c3) stage and $(c 5, c 6)$ stages, and in MPSDp after (c3) stage. These results corroborate with the findings of Baccetti et al. ${ }^{13}$ who concluded that RME treatment performed before pubertal peak group $(\mathrm{c} 1, \mathrm{c} 2, \mathrm{c} 3)$ stages showed significant skeletal effects when compared to the other late group $(\mathrm{c} 4, \mathrm{c} 5, \mathrm{c} 6)$ stages.In other words, the significant increase of MPDS after puberty could be the reason for the decreasing of skeletal effects of RME.

The outcomes of the current study showed that MPSD are low before (c4) stage, which may explain why it is better to perform RME treatment before that stage. Similarly, Angelieri et $\mathrm{al}^{12}$ concluded that CVMI could be used to determine the morphological stages of MPS, and depending on CVMI, RME treatment should be performed before (c4) stage. Thadani et al. ${ }^{34}$ also assumed that it is best to carry out RME before (c4)stage.

From the other point of view, several studies have demonstrated that MPS isn't the only region of resistance to expansion,circummaxillary sutures (such as the zygomaticomaxillary, zygomaticotemporal, and pterygopalatine sutures) $)^{35,36}$ and maxillary buttresses such as (piriform aperture, zygomatic buttresses, and pterygoid junctions) $)^{1,3,7}$ can also influence the success of RME. On the contrary, Lee et al. ${ }^{37}$ concluded that MPS is the definitive factor, and the surgical separation of it to assist RME in adults showed the same results of the separation of the pterygopalatine suture or Le Fort I corticotomy. Acar et al. ${ }^{7}$ found a highly significant correlation between MPS and maxillary buttresses density and the intermolar angle increase (which may reflect alveolar bending and decreasing of skeletal effects of RME). Thus the increasing MPSD with skeletal age may decrease the skeletal effects in adults. However, more research is needed to determine the effect of the development of circummaxillary sutures and maxillary buttresses on maxillary resistance to RME.

Despite the significant spurt in MPSD after puberty in this study, the low MPSD values recorded in some adult patients may clarify the success of RME in such age category. This agrees with other studies pointed to inter-individual adults variation in MPS maturation. $89,12,17$ In such patients, good skeletal effects could be achieved using RME despite their advanced CVMs. Likewise, Angelieri et al. ${ }^{12}$ found that in postpubertal patients, a CBCT assessment of morphological stages of MPS could help in determining the choice between RME or SARME. 
The high MPSD values recorded in the current study in some prepubertal patients may indicate that they would probably have limited skeletal effects if RME is applied.

\section{CONCLUSION}

To our best knowledge, this is the first study to explore the changes of MPSD in accordance with skeletal maturation. It is concluded that MPSD it increases with skeletal maturation advancement and it increases significantly afterpuberty, thus the skeletal effects of RME may decrease. The variety of bone densities in some maturation groups may explain the variety of RME success in adults.

\section{CLINICAL SIGNIFICANCE}

The assessment of the midpalatal suture density is very important to choose between RME and SARME when treating patients with maxillary constriction. The current study revealed a significant increase in themidpalatal suture density after puberty. Thus, it may better to perform RME before puberty.

\section{REFERENCES}

1. Sygouros A, Motro M, Ugurlu F, Acar A. Surgically assisted rapid maxillary expansion: cone-beam computed tomography evaluation of different surgical techniques and their effects on the maxillary dentoskeletal complex. Am J Orthod Dentofacial Orthop. 2014;146:748-757.

2. Proffit WR, Fields HW, Sarver DM. Orthodontic Treatment Planning: Limtaions,Controversies, and Special Problems. In: Proffit WR, Fields HW, Sarver DM, editors. Contemporary Orthodontics. 4th ed. St.Louis: Mosby Elsevier; 2007. p. $284,285,286$.

3. Suri L, Taneja P. Surgically assisted rapid palatal expansion: a literature review. Am J Orthod Dentofac Orthop. 2008;133:290-302.

4. Angell EC. Treatment of irregularities of the permanent or adult teeth. Dent Cosmos. 1860;1:599-601.

5. Haas AJ. Palatal expansion: just the beginning of dentofacial orthopedics. Am J Orthod Dentofac Orthop. 1970;57:219-255.

6. Haas AJ. Rapid Expansion of the Maxillary dental arch and nasal cavity by opening the midpalatal suture. Angle Orthod. 1961;31:73-90.

7. Acar YB, Motro M, Erverdi AN. Hounsfield Units: A new indicator showing maxillary resistance in rapid maxillary expansion cases? Angle Orthod. 2014;85:109-116.

8. Korbmacher H, Schilling A, Püschel K, Amling M, KahlNieke B. Age-dependent three-dimensional microcomputed tomography analysis of the human midpalatal suture. J Orofac Orthop. 2007;68:364-376.

9. Knaup B, Yildizhan F, Wehrbein H. Age-related changes in the midpalatal suture. A histomorphometric study. J Orofac Orthop. 2004;65:467-474.

10. Wehrbein H, Yildizhan F. The mid-palatal suture in young adults. A radiological-histological investigation. Eur J Orthod. 2001;23:105-114.
11. Revelo B, Fishman LS. Maturational evaluation of ossification of the midpalatal suture. Am J Orthod Dentofac Orthop. 1994;105:288-292.

12. Angelieri F, Franchi L, Cevidanes LHS, McNamara JA. Diagnostic performance of skeletal maturity for the assessment of midpalatal suture maturation. Am J Orthod Dentofac Orthop. 2015;148:1010-1016.

13. Baccetti T, Franchi L, Cameron CG, McNamara JA. Treatment timing for rapid maxillary expansion. Angle Orthod. 2001;71:343-350.

14. Grünheid T, Larson CE, Larson BE. Midpalatal suture density ratio: A novel predictor of skeletal response to rapid maxillary expansion. Am J Orthod Dentofac Orthop. 2017;151:267-276.

15. Koudstaal MJ, Poort LJ, van der Wal KGH, Wolvius EB, Prahl-Andersen B, Schulten AJM. Surgically assisted rapid maxillary expansion (SARME): a review of the literature. Int J Oral Maxillofac Surg. 2005;34:709-714.

16. Liu S, Xu T, Zou W. Effects of rapid maxillary expansion on the midpalatal suture: a systematic review. Eur J Orthod. 2015;37:651-655.

17. Angelieri F, Cevidanes LHS, Franchi L, Gonçalves JR, Benavides E, McNamara J a. Midpalatal suture maturation: Classification method for individual assessment before rapid maxillary expansion. Am J Orthod Dentofac Orthop. 2013;144:759-769.

18. Angelieri F, Franchi L, Cevidanes LHS, Gonçalves JR, Nieri M, Wolford LM, et al. Cone beam computed tomography evaluation of midpalatal suture maturation in adults. Int J Oral Maxillofac Surg. 2017;46:1557-1561.

19. Tonello DL, Ladewig V de M, Guedes FP, Ferreira Conti AC de C, Almeida-Pedrin RR, Capelozza-Filho L. Midpalatal suture maturation in 11- to 15-year-olds: A cone-beam computed tomographic study. Am J Orthod Dentofac Orthop. 2017;152:42-48.

20. Baccetti T, Franchi L, McNamara JA. An improved version of the cervical vertebral maturation (CVM) method for the assessment of mandibular growth. Angle Orthod. 2002;72:316-323.

21. Landis JR, Koch GG. The measurement of observer agreement for categorical data. Biometrics. 1977;33:159-174.

22. Dahiya K, Kumar N, Bajaj P, Sharma A, Sikka R, Dahiya S. Qualitative Assessment of Reliability of Cone-beam Computed Tomography in evaluating Bone Density at Posterior Mandibular Implant Site. J Contemp Dent Pr. 2018;19:426-430.

23. Cassetta M, Stefanelli LV, Pacifici A, Pacifici L, Barbato E. How accurate is $\mathrm{CBCT}$ in measuring bone density? A comparative CBCT-CT in vitro study. Clin Implant Dent Relat Res. 2014;16:471-478.

24. González-García R, Monje F. The reliability of cone-beam computed tomography to assess bone density at dental implant recipient sites: a histomorphometric analysis by micro-CT. Clin Oral Implants Res. 2013;24:871-879.

25. Han S, Bayome M, Lee J, Lee Y-J, Song H-H, Kook Y-A. Evaluation of palatal bone density in adults and adolescents for application of skeletal anchorage devices. Angle Orthod. 2012;82:625-631.

26. Lagravère MO, Fang Y, Carey J, Toogood RW, Packota G V, Major PW. Density conversion factor determined using a cone-beam computed tomography unit NewTom QR-DVT 9000. Dentomaxillofac Radiol. 2006;35:407-409. 
27. Razi T, Niknami M, Alavi Ghazani F. Relationship between Hounsfield Unit in CT Scan and Gray Scale in CBCT. J Dent Res Dent Clin Dent Prospects. 2014;8:107-110.

28. Poggio PM, Incorvati C, Velo S, Carano A. "Safe Zones": A Guide for Miniscrew Positioning in the Maxillary and Mandibular Arch. Angle Orthod. 2006;76:191-197.

29. Pauwels R, Nackaerts O, Bellaiche N, Stamatakis H, Tsiklakis $\mathrm{K}$, Walker A, et al. Variability of dental cone beam CT grey values for density estimations. Br J Radiol. 2013;86:20120135.

30. Parsa A, Ibrahim N, Hassan B, Motroni A, van der Stelt P, Wismeijer D. Reliability of voxel gray values in cone beam computed tomography for preoperative implant planning assessment. Int J Oral Maxillofac Implants. 2012;27:1438.

31. Parsa A, Ibrahim N, Hassan B, van der Stelt P, Wismeijer D. Bone quality evaluation at dental implant site using multislice CT, micro-CT, and cone beam CT. Clin Oral Implants Res. 2015;26:e1-7.

32. Nomura $Y$, Watanabe H, Honda E, Kurabayashi T. Reliability of voxel values from cone-beam computed tomography for dental use in evaluating bone mineral density. Clin Oral Implants Res. 2010;21:558-562.
33. Naitoh M, Hirukawa A, Katsumata A, Ariji E. Evaluation of voxel values in mandibular cancellous bone: relationship between cone-beam computed tomography and multislice helical computed tomography. Clin Oral Implants Res. 2009;20:503-506.

34. Thadani M, Shenoy U, Patle B, Kalra A, Goel S, Toshinawal N. Midpalatal Suture Ossification and Skeletal Maturation : A Comparative Computerized Tomographic Scan and Roentgenographic Study. J Indian Acad Oral Med Radiol. 2010;22:81-87.

35. Bell WH, Jacobs JD. Surgical-orthodontic correction of horizontal maxillary deficiency. J Oral Surg. 1979;37:897902.

36. Chaconas SJ, Caputo AA. Observation of orthopedic force distribution produced by maxillary orthodontic appliances. Am J Orthod. 1982;82:492-501.

37. Lee SC, Park JH, Bayome M, Kim KB, Araujo EA, Kook Y-A. Effect of bone-borne rapid maxillary expanders with and without surgical assistance on the craniofacial structures using finite element analysis. Am J Orthod Dentofac Orthop. 2014;145:638-648. 